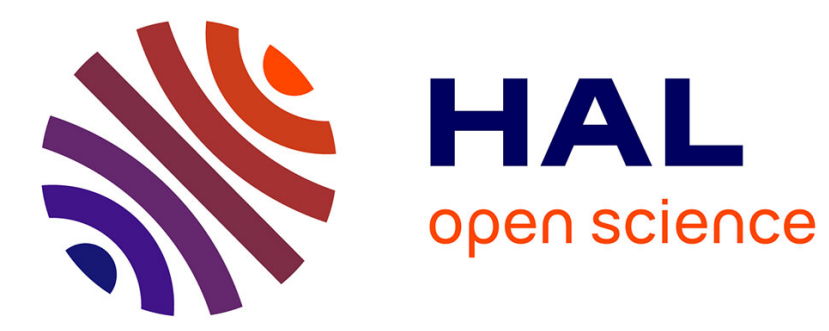

\title{
Layer thickness and the shape of faults
}

Antonio Benedicto, R.A. Schultz, R. Soliva

\section{To cite this version:}

Antonio Benedicto, R.A. Schultz, R. Soliva. Layer thickness and the shape of faults. Geophysical Research Letters, 2003, 30, 20 (20), pp.2076-2079. 10.1029/2003GL018237 . hal-00068606

\section{HAL Id: hal-00068606 https://hal.science/hal-00068606}

Submitted on 28 Jan 2021

HAL is a multi-disciplinary open access archive for the deposit and dissemination of scientific research documents, whether they are published or not. The documents may come from teaching and research institutions in France or abroad, or from public or private research centers.
L'archive ouverte pluridisciplinaire HAL, est destinée au dépôt et à la diffusion de documents scientifiques de niveau recherche, publiés ou non, émanant des établissements d'enseignement et de recherche français ou étrangers, des laboratoires publics ou privés. 


\title{
Layer thickness and the shape of faults
}

\author{
A. Benedicto \\ Dept. Sciences de la Terre, OrsayTerre, Univ. Paris XI, France
}

R. A. Schultz

Dept. Geological Sciences, Geomechanics-Rock Fracture Group, Mackay School of Mines, Univ. of Nevada, Reno, USA

\section{R. Soliva}

Dept. Sciences de la Terre, OrsayTerre, Univ. Paris XI, France

Received 23 July 2003; revised 17 September 2003; accepted 25 September 2003; published 31 October 2003.

[1] We analyze from a conceptual point of view, the role of layer thickness on fault vertical restriction, size distribution and shape evolution. We propose a model of fault growth from an initially circular/elliptical shape of individual (but kinematically interrelated in a coherent fault zone) fault segments to a final rectangular shape. Faults (or fault segments) that do not interact strongly with the stratigraphy grow vertically as nonrestricted with circular to elliptical shapes. Linkage of those faults leads to elliptical shapes for large composite faults. In contrast, faults (or fault segments) whose vertical growth is restricted by the layer thickness evolve from circular to elliptical with progressively larger aspect ratios. In a sequence with heterogeneous strength and varying layer thickness, individual faults within each layer are restricted, producing a complex irregular tipline for the aggregate large fault. The irregular geometry will persist as long as the tendency for horizontal fault growth exceeds that for linkage; once linkage across layers occurs, then more regular elliptical tiplines will evolve. Because longer faults have larger displacements, then for brittle strain to be equal in layers of different thickness, more faults are needed in thin layers for the total displacements, and thus the strains, to balance. As a result, irregular fault shapes can evolve as more new faults grow in thinner layers into more rectangular shapes. INDEX TERMS: 5104 Physical Properties of Rocks: Fracture and flow; 5475 Planetology: Solid Surface Planets: Tectonics (8149); 8010 Structural Geology: Fractures and faults; 8109 Tectonophysics: Continental tectonics - extensional (0905); 8110 Tectonophysics: Continental tectonics-general (0905). Citation: Benedicto, A., R. A. Schultz, and R. Soliva, Layer thickness and the shape of faults, Geophys. Res. Lett., 30(20), 2076, doi:10.1029/2003GL018237, 2003.

\section{Introduction}

[2] The literature provides many clear examples from 3D seismic analysis and analogue modeling in which largescale faults have a rectangular shape (Figure 1) [e.g., Childs et al., 1995; Leveille et al., 1997; Guglielmo et al., 2000; Kattenhorn and Pollard, 2001; Marchal et al., 2003]; today, seismic interpreters in petroleum companies and 3D seismics visualization software construct 3D fault models with rectangular fault shapes. This approach contrasts with the conceptual circular to elliptical shape proposed by numer- ous authors for single faults (Figure 2a) [e.g., Barnett et al., 1987; Walsh and Watterson, 1989; Willemse, 1994], and which is typically used in numerical modeling of fault growth and linkage [e.g., Willemse et al., 1996; Willemse, 1997; Crider and Pollard, 1998; Maerten et al., 1999]. Although faults with circular or elliptical tiplines may be in general poorly illustrated by real examples, they provide a starting point from which to consider how layering might impact on fault shape. On the other hand, there exists an incomplete understanding of the evolution of fault shape from the scale of a single fault to the scale of a large, composite fault comprising multiple soft- or hard-linked segments.

[3] Nicol et al. [1996] suggest that restricted faults due to layering or mechanical anisotropy tend to have horizontal, elongated elliptical shapes. Recent work emphasizes the role of vertical fault restriction on the elliptical elongated fault shape (Figure 2b) [R. Soliva and A. Benedicto, Geometry, scaling relations and spacing of restricted normal faults, submitted to J. Struct. Geol., 2003], with lengths as much as 8 times the height.

[4] Growth by fault linkage can also lead to irregular elongated ellipses [e.g., Willemse, 1994; Willemse et al., 1996]. Mansfield and Cartwright [1996] argue that the

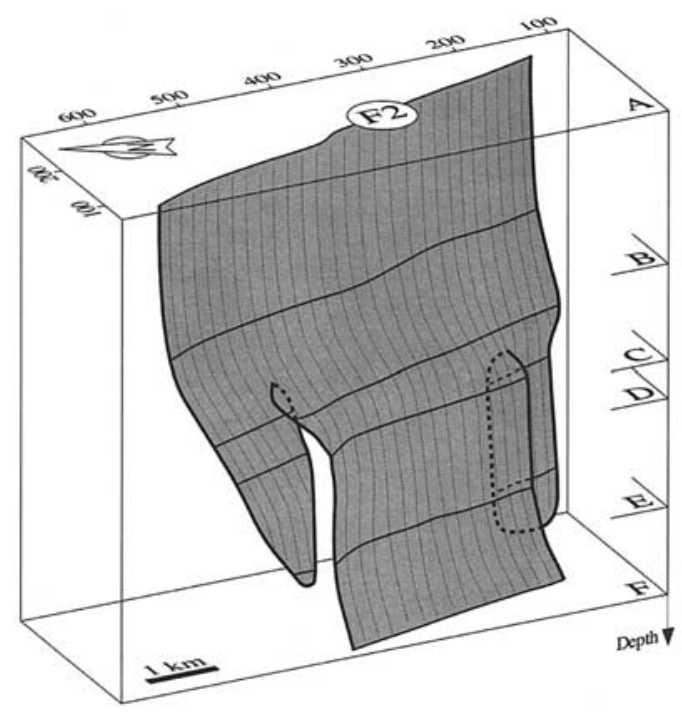

Figure 1. Rectangular shape of a fault from 3D seismic data, from Marchal et al. [2003].

$13-1$ 
FAULT SHAPE EVOLUTION

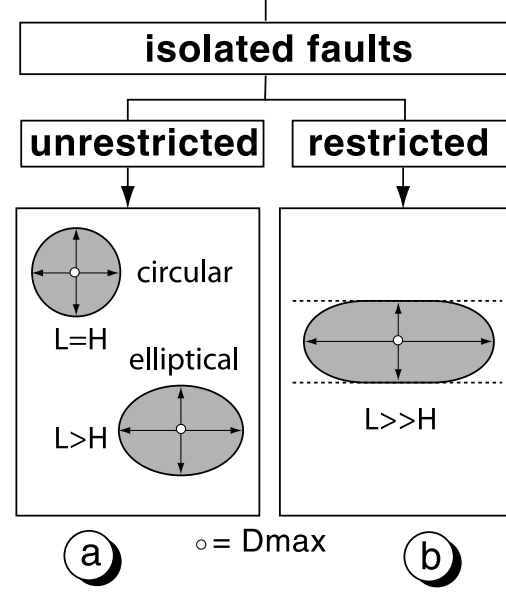

Sketches represent frontal views of faults. Fault planes are the dark grey areas. The white small circle within faults locates the maximum displacement. Horizontal dashed lines represent layers, grey tones represent different thickness. Note that for equal brittle strains to be accommodated in layers of unequal thickness, more faults are needed in thinner layers than in thicker ones.
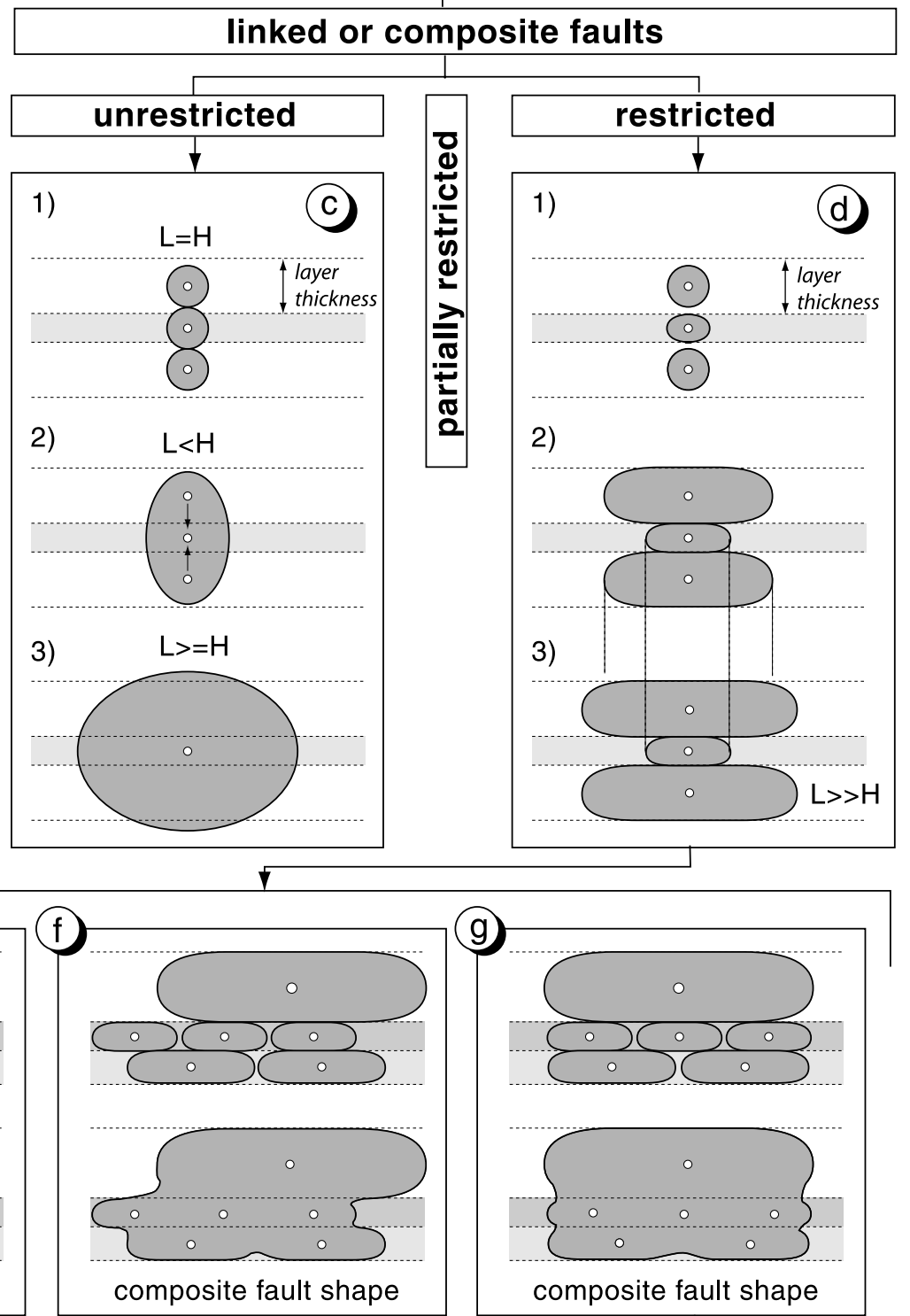

IRREGULAR

IRREGULAR to SUB-RECTANGULAR

RECTANGULAR

Figure 2. Sketch illustrating fault growth evolution from an initially circular/elliptical shape of individual faults to a final rectangular shape of vertically restricted, composite (linked) fault. The controlling parameter of the fault vertical restriction, size distribution and shape evolution is the layer thickness.

coalescence of initially elliptical fault segments leads to shapes elongated parallel to the fault strike direction. In their conceptual model (see their Figure 12) they suggest without elaboration that fault linkage may lead to nearly rectangular final fault shapes.

[5] Is the rectangular shape of large faults real or an artifact of seismic data? If it is real, how is their shape related to the circular/elliptical shapes? The purpose of this paper is to answer affirmatively to these two questions, and to propose a conceptual model of fault growth from an initially circular/elliptical shape of individual (but kinematically interrelated in a coherent fault zone) fault segments to a final rectangular shape of vertically restricted, composite (soft- or hard-linked) fault segments. The controlling parameter identified here is the layer thickness managing the fault vertical restriction, size distribution and shape evolution.

[6] The proposed model is developed considering a stratigraphic sequence having layers of variable thickness, with the same strength, and separated by mechanical discontinuities. This has major implications for 3D fault segmentation, fault distribution in heterogeneous sequences, reservoir fracturing and prediction, and fault transmissivity properties associated with fault displacement gradients.

\section{Vertical Fault Restriction}

[7] In layered sequences, the vertical fault height can be limited, or restricted, by the thickness of the lithologic layer [e.g., Nicol et al., 1996; Gross et al., 1997; Wilkins and 
Gross, 2002]. Restricted faults with length higher than the vertical height are characterized by larger values of near-tip displacement gradients vertically than horizontally. Vertical restriction occurs when the typical properties of the interface or adjacent layer inhibit and prevent propagation of the fault tip across the sequence; continued horizontal propagation within the layer leads to elliptical restricted faults parallel to bedding. In contrast, smaller faults in layered sequences [e.g., Willemse, 1997], and faults in massive, nonlayered units such as granitic plutons [e.g., Martel and Boger, 1998], may not be vertically restricted and can have vertical near-tip gradients comparable to those along the horizontal axis of the fault [Walsh and Watterson, 1988; Crider and Pollard, 1998; Kattenhorn and Pollard, 2001].

[8] Mechanical interaction between faults can also lead to larger values of displacement and tip gradients, comparable to those of restricted faults, for fault geometries that impede propagation [e.g., Segall and Pollard, 1980; Crider and Pollard, 1998; Gupta and Scholz, 2000; Kattenhorn and Pollard, 2001]. Downdip linkage of faults commonly occurs at lithologic contacts [e.g., Wilkins and Gross, 2002], indicating a physical relationship between layering, vertical restriction and fault segmentation.

[9] In summary, stratigraphic layering can control the vertical dimensions of faults and fault segments as long as a sufficiently large contrast in material properties exists between the layers. Fault restriction can thus be achieved either for inhomogeneous sequences (e.g., interbedded sandstones/shales [Wilkins and Gross, 2002]) or for homogeneous lithologies separated by either thin beds or weak interfaces [Cooke and Underwood, 2001]. In this paper we focus on the latter case, which is commonly found in carbonate or sandstone units, cut by discrete fault segments, and separated by thin shale beds [e.g., Wilkins and Gross, 2002]. Although many authors [Mandl, 1987; Childs et al., 1995; Marchal et al., 2003; Walsh et al., 2003] have suggested that in many cases vertical fault segmentation is produced by fault propagation through a multi-layer, here we note that discrete fault segments may appear and propagate individually in sufficiently different layers, all along a kinematically coherent fault zone.

\section{Horizontal Fault Length and Layer Thickness}

[10] Growth of unrestricted faults can produce nearly circular or elliptical shapes [e.g., Nicol et al., 1996; Martel and Boger, 1998] if the rock strength is comparable along the fault tipline [e.g., Cowie and Scholz, 1992]. On the other hand, continued horizontal growth of vertically restricted faults is well documented in clay models [e.g., Ackermann et al., 2001] and in the field [e.g., Cowie et al., 1993; Scholz, 1997], leading to an increase in the aspect ratio (length/height) [Willemse et al., 1996; Gudmundsson, 2000; Schultz and Fossen, 2002].

[11] The increase in aspect ratio limits the eventual length of a restricted fault. As noted by [Willemse et al., 1996; Gudmundsson, 2000; Schultz and Fossen, 2002], the displacement gradients vary along the restricted fault, being larger along the vertical direction and smaller along the horizontal one. Although it might be thought that a restricted fault could increase in length indefinitely, its ability to accumulate displacement degrades with increasing length [Willemse et al., 1996; Schultz and Fossen, 2002]. Eventually, at some value of length, the displacement gradient at the horizontal tip of a restricted large-aspectratio fault decreases below the critical value [e.g., Cowie and Scholz, 1992; Scholz, 1997] necessary for propagation [e.g., Gupta and Scholz, 2000]. As a result, horizontal growth of a restricted fault ceases, leading to a maximum length that depends on the layer thickness. Thus, layer thickness controls both the vertical height and the maximum horizontal length of restricted faults.

\section{Fault Growth Across the Stratigraphy}

[12] Given the relationships between layer thickness, vertical restriction, and horizontal fault length discussed above, the shape of a growing segmented fault will evolve along either of two opposed paths: nonrestricted or restricted (right-hand side of Figure 2). The final shape of a large, composite fault, however, whose height exceeds layer thickness, depends additionally on the strength contrasts between the layers. The strength characteristics of layered sequences determine whether large faults maintain their elliptical shape or produce irregular or rectangular shapes.

[13] Faults that do not interact strongly with the stratigraphy (i.e., in massive or mechanically homogeneous units), or with nearby isolated faults, will begin and continue to grow as nonrestricted faults with circular to elliptical shapes (Figure 2a). Interaction and linkage of faults (or fault segments) within this sequence leads to vertical growth and, eventually, elliptical shapes for large composite faults (Figure 2c) [e.g., Cowie et al., 2000] (case considered by Nicol et al. [1996] and by Walsh et al. [2003] in their studies of fault shape).

[14] In contrast, faults whose vertical dimensions and growth are limited by the layer thickness (Figure 2b) evolve from circular to elliptical shapes with progressively larger aspect ratios. In the case of a faulted stratigraphic sequence with heterogeneous strength due to layering and varying layer thickness, individual faults within each layer are restricted [Nicol et al., 1996], producing a complex irregular tipline for the aggregate large fault (Figure 2d). The irregular geometry will persist as long as the tendency for horizontal fault growth exceeds that for vertical linkage; once linkage across layers occurs, then more regular elliptical tiplines will evolve (Figure 2c).

[15] An irregular fault shape such as shown in Figure 2e represents an unstable configuration that will evolve with time. For equal brittle strains to be accommodated in layers of unequal thickness, more faults are needed in thinner layers than in thicker ones. This comparison assumes comparable values of deformability for each layer, as documented for different rocktypes at appropriate field scales [e.g., Bieniawski, 1978]. For example, for a layer with a single restricted 2D-fault, the normal strain $\varepsilon=$ $(D L H) / V=(D L H) /(L H W)$, where $D$ is maximum fault displacement (the heave component), $L$ is fault length, $H$ is fault height, and $W$ is measured normal to the fault plane (for given dip angle [Scholz, 1997; Schultz, 2003]). Since $W$ is proportional to the fault dimensions [e.g., Barnett et al., 1987], $\varepsilon$ is proportional to $D$. Because longer faults have larger displacements, then for brittle strain to be equal in layers of different thickness, more faults are needed in thin 
layers for the total displacements, and thus the strains, to balance. As a result, irregular fault shapes (Figure 2e) will evolve as more new faults grow in thinner layers into more rectangular shapes (Figures $2 \mathrm{f}$ and $2 \mathrm{~g}$ ).

\section{Conclusions and Implications}

[16] We highlight the role of layer thickness in vertical fault restriction and in the evolution of fault shape. We propose that the homogeneous vs. heterogeneous mechanical strength of many layered sequences can produce the variety of fault shapes that are observed in nature, including circular, elliptical, irregular, and rectangular. This may explain why faults observed in 3D high-resolution seismic data or from 4D analog models [e.g., Marchal et al., 2003] within layered sequences commonly exhibit rectangular shapes.

[17] The fault growth model (here referred to segmented faults) implies a greater number of fault segments in thinner layers than in thicker ones which in turn suggests a greater degree of fault segmentation and displacement heterogeneity in thinner layers. As vertical restriction reduces the ability of faults to link vertically, individual (soft- or hardlinked) fault segments will persist longer, so large-scale faults will preserve more segmentation in mechanically heterogeneous sequences than those in homogeneous sequences. The mechanical properties of the stratigraphy thus determine both the final shape of larger faults (circular/ elliptical versus rectangular) and their slip distribution, which controls the associated properties along the fault zone (e.g., transmissivity and fault sealing). We infer that the architecture and physical properties of large crustal faults depend critically on the mechanical heterogeneity of the stratigraphic sequence.

[18] Acknowledgments. We thank the Dept. Sciences de la Terre and the University Paris XI for funding the visit of R. A. Schultz to the University Paris XI, and A. Nicol and the Associate Editor for review comments that sharpened the focus of this paper.

\section{References}

Ackermann, R. V., R. W. Schlische, and M. O. Withjack, The geometric and statistical evolution of normal fault systems, J. Struct. Geol., 23, $1803-$ 1819, 2001

Barnett, J. A. M., J. Mortimer, J. H. Rippon, J. J. Walsh, and J. Watterson, Displacement geometry in the volume containing a single normal fault, AAPG Bull., 71, 925-937, 1987.

Bieniawski, Z. T., Determining rock mass deformability: Experience from case histories, Int. J. Rock Mech. Min. Sci., 15, 237-247, 1978.

Childs, C., J. Watterson, and J. J. Walsh, Fault overlap zones within developing normal fault systems, J. Geol. Soc. London, 152, 535-549, 1995.

Cooke, M. L., and C. A. Underwood, Fracture termination and step-over at bedding interfaces due to frictional slip and interface opening, J. Struct. Geol., 23, 223-238, 2001.

Cowie, P. A., S. Gupta, and N. Dawers, Implications of fault array evolution for synrift depocentre development, Basin Res., 12, 241-261, 2000.

Cowie, P. A., and C. H. Scholz, Displacement-length scaling relationship for faults, J. Struct. Geol., 14, 1149-1156, 1992.

Cowie, P. A., C. H. Scholz, A. Malinverno, and M. H. Edwards, Fault strain and seismic coupling on the East Pacific Rise, J. Geophys. Res., 98 , $17,911-17,920,1993$.
Crider, J. G., and D. D. Pollard, Fault linkage: Three-dimensional mechanical interaction between echelon normal faults, J. Geophys. Res., 103, 24,372-24,391, 1998.

Gross, M. R., G. Gutierrez-Alonso, T. Bai, M. A. Wacker, K. B. Collinsworth, and R. J. Behl, Influence of mechanical stratigraphy and kinematics on fault scaling relations, J. Struct. Geol., 19, 171-183, 1997.

Gudmundsson, A., Fracture dimensions, displacements and fluid transport, J. Struct. Geol., 22, 1221-1231, 2000.

Guglielmo, J. G., B. C. Vendeville, and M. P. A. Jackson, 3-D visualization and isochore analysis of extensional diapers overprinted by compression, AAPG Bull., 84, 1095-1108, 2000.

Gupta, A., and C. H. Scholz, A model of normal fault interaction using observations and theory, J. Struct. Geol., 22, 865-879, 2000.

Kattenhorn, S. A., and D. D. Pollard, Integrating 3D seismic data, field analogs and mechanical models in the analysis of segmented normal faults in the Wytch Farm oil field, southern England, AAPG Bull., 85, $1183-1210,2001$.

Leveille, G. P., R. Knipe, C. More, D. Ellis, G. Dudley, G. Jones, Q. J. Fisher, and G. Allinson, Compartmentalization of rotliegendes gas reservoirs by sealing faults, Jupiter field area, southern North Sea, in Petroleum Geology of the Southern North Sea, edited by K. Ziegler, P. Turner, and S. R. E. Daines, pp. 87-104, Geol. Soc. London Spec. Publ., 1997.

Maerten, L., J. M. Willemse, D. D. Pollard, and K. Rawnley, Slip distributions on intersecting normal faults, J. Struct. Geol., 21, 259-271, 1999.

Mandl, G., Discontinuous fault zones, J. Struct. Geol., 9, 105-110, 1987.

Mansfield, C. S., and J. A. Cartwright, High resolution fault displacement mapping from three-dimensional seismic data: Evidence for dip linkage during fault growth, J. Struct. Geol., 18, 249-263, 1996.

Marchal, D., M. Guiraud, and T. Rives, Geometric and morphological evolution of normal fault planes and traces from 2D to 4D data, J. Struct. Geol., 25, 135-158, 2003.

Martel, S. J., and W. A. Boger, Geometry and mechanics of secondary fracturing around small three-dimensional faults in granitic rocks, J. Geophys. Res., 103, 21,299-21,314, 1998.

Nicol, A., J. J. Watterson, J. Walsh, and C. Childs, The shapes, major axis orientations and displacement patterns of fault surfaces, J. Struct. Geol., 18, 235-248, 1996.

Scholz, C. H., Whatever happened to earthquake prediction, Geotimes, 16 - 19, March, 1997.

Schultz, R. A., A method to relate elastic stress to fault population strains, Geophys. Res. Lett., 30, 1593, doi:10.1029/2002GL016681, 2003.

Schultz, R. A., and H. Fossen, Displacement-length scaling in three dimensions, J. Struct. Geol., 24, 1389-1411, 2002.

Segall, P., and D. D. Pollard, Mechanics of discontinuous faulting, J. Geophys. Res., 85, 4337-4350, 1980 .

Walsh, J. J., and J. Watterson, Analysis of the relationship between displacements and dimensions faults, J. Struct. Geol., 10, 239-247, 1988.

Walsh, J. J., and J. Watterson, Displacement gradients on fault surfaces, J. Struct. Geol., 11, 307-316, 1989.

Walsh, J. J., W. R. Bailey, C. Childs, A. Nicol, and C. G. Bonson, Formation of segmented normal faults: A 3-D perspective, J. Struct. Geol., 25, 1251-1262, 2003.

Wilkins, S. J., and M. R. Gross, Normal fault growth in layered rocks at Split Mountain, Utah, J. Struct. Geol., 24, 1413-1429, 2002.

Willemse, E. J. M., Segmented normal faults: Correspondence between three-dimensional mechanical models and field data, J. Geophys. Res., 102, 675-692, 1997.

Willemse, E. J. M., D. D. Pollard, and A. Aydin, Three-dimensional analyses of slip distributions on normal fault arrays with consequences for fault scaling, J. Struct. Geol., 18, 295-309, 1996.

Willemse, E. J. M., The geometry and mechanics of segmented normal faults. Stanford Univ., Stanford Rock Fracture Project, vol. 5, 15 p., 1994.

A. Benedicto and R. Soliva, Dept. Sciences de la Terre, OrsayTerre, bât. 504, Université Paris XI, 91405 Orsay, France. (benedicto@geol.u-psud.fr) R. A. Schultz, Dept. Geological Sciences/172, Geomechanics-Rock Fracture Group, Mackay School of Mines, University of Nevada, Reno, NV 89557-0138, USA. (schultz@mines.unr.edu) 